07,01

\title{
Деформационное поведение и структура квазикристаллического сплава $i$-Al-Cu-Fe в окрестности отпечатка наноиндентора
}

\author{
() Е.В. Шалаева ${ }^{1}$, И.О. Селянин ${ }^{1,2}$, Е.О. Смирнова ${ }^{3}$, С.В. Смирнов ${ }^{3}$, Д.Д. Новачек ${ }^{2}$ \\ ${ }^{1}$ Институт химии твердого тела УрО РАН, \\ Екатеринбург, Россия \\ ${ }^{2}$ Уральский федеральный университет им. Б.Н. Ельцина, \\ Екатеринбург, Россия \\ ${ }^{3}$ Институт машиноведения УрО РАН, \\ Екатеринбург, Россия \\ E-mail: shalaeva@ihim.uran.ru
}

(Поступила в Редакцию 19 июня 2017 г.)

Для квазикристаллического полизеренного сплава $\mathrm{Al}_{62.4} \mathrm{Cu}_{25.3} \mathrm{Fe}_{12.3}$ с икосаэдрической структурой $i$ выполнены тесты наноиндентирования, по диаграммам нагрузка $(P)$-смещение $(h)$ оценены вклады пластической деформации (монотонной и прерывистой) и проведены электронно-микроскопические исследования структуры поперечных срезов в окрестности отпечатков индентора. Показано, что в упруго-пластической зоне в окрестности отпечатка формируется несколько систем деформационных полос по плотноупакованным плоскостям $i$-решетки с осями симметрии пятого и второго порядка, полосы нередко начинаются от трещин и проявляют признаки дислокационной структуры. Следы фазового превращения с образованием частиц $\beta$-фазы обнаружены только в тонком слое под индентором. Эффекты прерывистой деформации составляют до 50\% от общей неупругой деформации и связываются с пластическим поведением квазикристалла активацией и прохождением деформационных полос, а также с образованием подповерхностных микро- и наноразмерных трещин.

Работа поддержана Российским фондом фундаментальных исследований (грант 16-02-00085).

DOI: 10.21883/FTT.2018.02.45385.199

\section{1. Введение}

Недавние разработки дисперсно-упрочненных сплавов [1-2] и покрытий [3-4] на основе квазикристаллических фаз $\mathrm{Al}-\mathrm{Tm}(\mathrm{Tm}-\mathrm{Fe}, \mathrm{Cu}, \mathrm{Cr})$ с икосаэдрической структурой вновь привлекают внимание к изучению деформационного поведения квазикристаллов. Наибольший интерес вызывает деформационное поведение при пониженных температурах. Как известно, при высоких температурах, квазикристаллические фазы $\mathrm{Al}-\mathrm{Tm}$ всегда пластичны, и для них возможен дислокационный механизм пластической деформации $[4,5]$. Термическая активация способствует движению дислокаций, затрудненному из-за кластерной структуры квазикристаллов и диффузионно-контролируемой фазонной компоненты вектора Бюргерса. Однако, при пониженных температурах механическое поведение квазикристаллов более существенно зависит от схемы деформации. В отличие от хрупкого поведения в тестах на сжатие и растяжение [4], $i$-квазикристаллы Al-Tm демонстрируют пластичность в условиях литостатического давления (confining pressure), когда одноосная нагрузка сочетается с высоким гидростатическим давлением до $\sim 10 \mathrm{GPa}[6,7]$. В этом случае электронномикроскопические исследования обнаружили дислокационные полосы сдвига, индивидуальные дислокации в полизеренных сплавах $i-\mathrm{Al}-\mathrm{Pd}-\mathrm{Mn}$ и $i-\mathrm{Al}-\mathrm{Cu}-\mathrm{Fe}$, что позволило предположить дислокационный механизм пластической деформации и атермическую активацию движения дислокаций в квазикристаллах в условиях confining pressure $[6,7]$.

Схема деформации, подобная условиям confining pressure, как предполагают, реализуется и в тестах нано-индентирования, но в ограниченном объеме материала [8]. В тестах индентирования, согласно зависимостям нагрузка $(P)$-смещение индентора $(h)$, квазикристаллические моно- и полизеренные сплавы, в том числе $i$-Al-Tm, также демонстрируют существенный вклад неупругой деформации при комнатных температурах [8-12]. Механизмы неупругой деформации квазикристаллов при наноиндентировании окончательно не выяснены. Вопрос осложняется также возможностью фазовых превращений под индентором, индуцированных высоким давлением [13,14]. Данные о структуре деформированных квазикристаллических сплавов ограничены. Электронно-микроскопические исследования поперечных срезов квазикристалла в окрестности отпечатка индентора выполнены только для сплава $i$-Al-Pd-Mn [15]. В зоне под отпечатком индентора не обнаружено следов фазового превращения, наблюдалось множество границ, нанотрещин, индивидуальные дислокации. В отличие от работ по тестам confining pressure был предложен бездислокационный механизм неупругой деформации квазикристаллов при пониженных температурах [15]. 
Для других квазикристаллических сплавов, в том числе и сплава $i-\mathrm{Al}-\mathrm{Cu}-\mathrm{Fe}$, представления о механизме неупругой деформации при наноиндентировании основываются на анализе эффектов нестабильности в виде множественных ступеней, часто наблюдаемых на диаграммах нагрузка-смещение $[8-10,12,14,16]$. Отдельные авторы связывают эти эффекты с собственными пластическими свойствами квазикристаллов, а именно, с образованием деформационных полос [12,14] или с движением индивидуальных дислокаций [16]. В ряде работ множественные ступени рассматриваются как результат индуцированных высоким давлением фазовых превращений квазикристалла в более пластичную кристаллическую фазу [8-10]. В качестве обоснования принимаются результаты электронно-микроскопического исследования поверхностного слоя толщиной не более $0.1 \mu \mathrm{m}$ полизеренного сплава $i$ - $\mathrm{Al}-\mathrm{Cu}-\mathrm{Fe}$ после скретчтеста (царапание наноиндентором) [17]. В поверхностном слое были обнаружены модулированная $i$-фаза, это переходное состояние превращения в кристаллический аппроксимант, и частицы $\beta$-фазы $\mathrm{Al}-\mathrm{Cu}-\mathrm{Fe}$. Однако, как следует из моделей состояния материала под отпечатком индентора [13] и результатов для сплава $\mathrm{Al}-\mathrm{Pd}-\mathrm{Mn}[15]$, зона упруго-пластической деформации существенно больше для характерных размеров отпечатков порядка нескольких микрон, а превращение может протекать только в узкой зоне гидростатического давления непосредственно под отпечатком. Таким образом, данные о структуре и характере деформации в области под отпечатком наноиндетора противоречивы, особенно это касается сплава $i$-Al- $\mathrm{Cu}-\mathrm{Fe}$, важного с точки зрения практических приложений.

В данной работе для того, чтобы прояснить микроскопические механизмы пластической деформации квазикристаллического сплава $i-\mathrm{Al}-\mathrm{Cu}-\mathrm{Fe}$ при наноиндентировании, были получены диаграммы нагрузка $(P)$-смещение $(h)$ и проведены оценки вкладов пластической деформации (монотонной и прерывистой). Параллельно выполнены электронно-микроскопические исследования деформированного состояния сплава в окрестности полученных отпечатков индентора с использованием методики поперечных срезов. Показано, что в основной упруго-пластической зоне в окрестности отпечатка формируется несколько систем деформационных полос с признаками дислокационной структуры. Признаки фазового превращения с образованием частиц $\beta$-фазы обнаружены только в тонком слое под индентором. Эффекты прерывистой деформации с вкладом до $50 \%$ в общую неупругую деформацию предлагается связывать с активацией и прохождением наблюдаемых деформационных полос, и частично, с образованием отдельных подповерхностных микрои наноразмерных трещин, обнаруженных в упругопластической зоне.

\section{2. Методическая часть}

2.1. Методики приготовления и анализа квазикристаллического сплава. Детали приготовления квазикристаллического сплава $\mathrm{Al}-\mathrm{Cu}-\mathrm{Fe}$ изложены в работе [18]. Локальный химический анализ выполнен методом электронно-зондового микроанализа на микроанализаторе Cameca SX 100 с ускоряющим напряжением $15 \mathrm{\kappa eV}$ и током $29 \mathrm{nA}$. Сплав имел состав $\mathrm{Al}_{62.4} \mathrm{Cu}_{25.3} \mathrm{Fe}_{12.3}$, стандартные отклонения в содержании компонентов $\mathrm{Al}, \mathrm{Fe}, \mathrm{Cu}$ составляли $0.14,0.09$ и 0.15 at.\% соответственно.

Совершенство квазикристаллической структуры и микроструктура сплава $\mathrm{Al}_{62.4} \mathrm{Cu}_{25.3} \mathrm{Fe}_{12.3}$ исследованы методом просвечивающей электронной микроскопии на приборе JEM 200-CX. Для электронномикроскопического исследования образцы сплава электролитически полировались в стандартной смеси $(60 \%$ метанол $+40 \%$ азотная кислота) после предварительного механического утонения. Для анализа электронно-дифракционных картин и обратной решетки квазикристаллической фазы использован метод проекций и сечений из 6-мерного пространства $[19,20]$. Расчетные сечения обратной решетки икосаэдрической фазы получены в трехмерной кубической системе координат с использованием матрицы проектирования $(3 \times 6)$. Индицирование дифракционных векторов $\mathbf{g}_{\|}\left(h / h^{\prime}, k / k^{\prime}, l / l^{\prime}\right)$ для $i$-фазы $\mathrm{AlCuFe}$ (в обратном пространстве 6Dрешетка ОЦК-типа) произведено в рамках ячейки, предложенной в работе [21]. Сопоставление расчетных и экспериментальных дифракционных картин выполнено с использованием алгоритмов обучения нейронных сетей.

По данным просвечивающей электронной микроскопии исходный отожженный сплав $\mathrm{Al}_{62.4} \mathrm{Cu}_{25.3} \mathrm{Fe}_{12.3}$ являлся однофазным, имел квазикристаллическую икосаэдрическую структуру. Размеры зерен составляли от 5 до $10 \mu \mathrm{m}$, наблюдались единичные внутризеренные дислокации. Типичное светлопольное электронномикроскопическое изображение и микродифракционная картина приведены на рис. $1, a$.

2.2. Методика индентирования и исследования структуры сплава в окрестности отпечатка. Тест наноиндентирования проведен на электролитически полированных образцах квазикристаллического сплава $\mathrm{Al}_{62.4} \mathrm{Cu}_{25.3} \mathrm{Fe}_{12.3}$. Диаграммы нагружения $P-h$ получены в режиме регистрации силы вдавливания $(P)$ и глубины отпечатка $(h)$ в процессе индентирования. Измерения выполнены с использованием комплекса для наномеханических испытаний TRIBOINDENTER TI900 и индентора FICHERSCOPE HM2000. В комплексе TRIBOINDENTER TI900 использован индентор Берковича с радиусом закругления $100 \mathrm{~nm}$. В приборе FICHERSCOPE измерения выполнены с использованием индентора Виккерса. Пиковые нагрузки составляли 50 и $75 \mathrm{mN}$, скорость нагружения $-2.5 \mathrm{mN} \cdot \mathrm{s}^{-1}$. Измерительные комплексы оснащены программой обработки кривых нагружения $P-h$ 


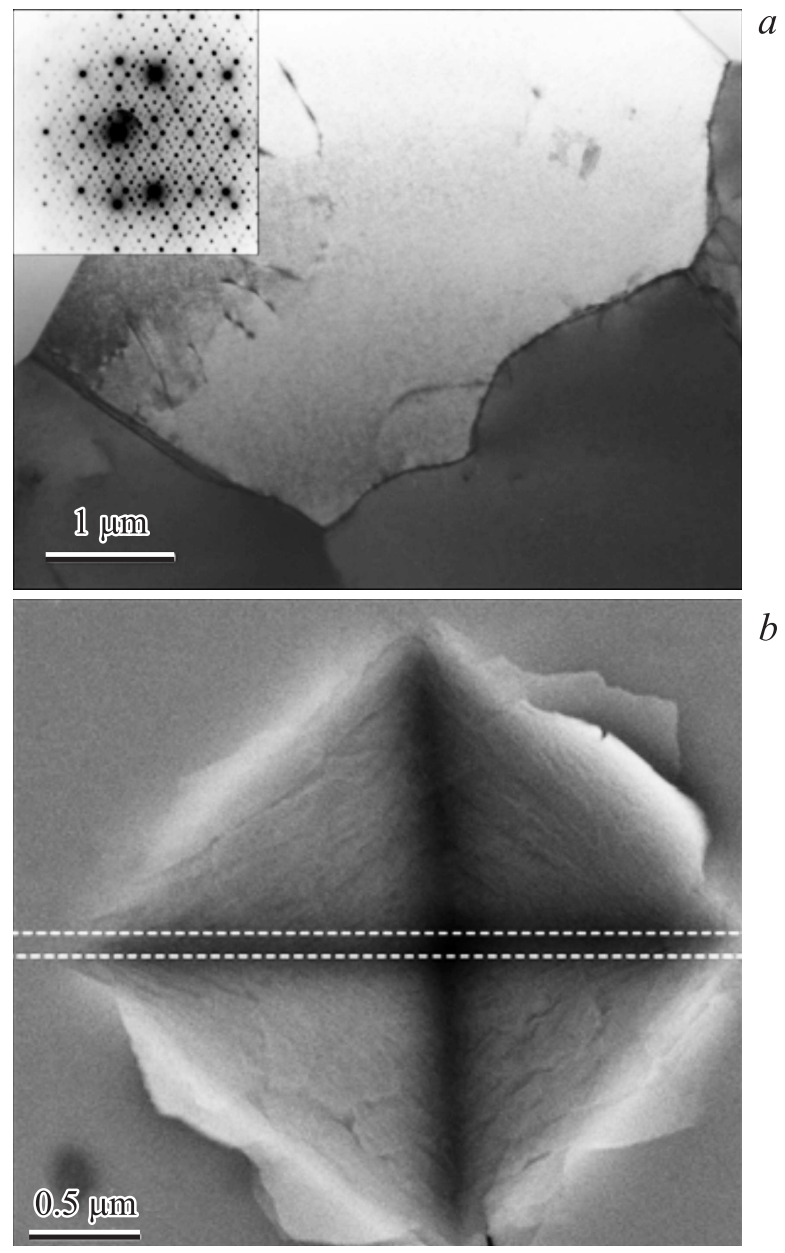

Рис. 1. Светлопольное электронно-микроскопическое изображение и микродифракционная картина (на вставке) квазикристаллического полизеренного сплава $i$ - $\mathrm{Al}_{62.4} \mathrm{Cu}_{25.3} \mathrm{Fe}_{12.3}$, ориентация фольги в направлении оси второго порядка $A 2(a)$. Изображение отпечатка индентора, нанесен след поперечного среза, выполненного методом сфокусированного ионного пучка $(\mathrm{FIB})(b)$.

по методике Оливера-Фарра, оценивающей значения контактной твердости $(H)$ и модуля упругости $(E)[22]$. Экспериментальные значения $H, E$ определялись по серии диаграмм нагружения (от 4 до 7). Контактное давление под индентором, рассчитанное из диаграмм $P-h$, имело значения в диапазоне от 13 до $8 \mathrm{GPa}$.

Изображения отпечатков индентора получены на сканирующем электронном микроскопе MIRA3 TESCAN. Следы трещин на изображениях поверхности отпечатков не выявлены (рис. 1,b). Структура квазикристаллического сплава в окрестности отпечатка индентора исследована методом просвечивающей электронной микроскопии (JEM 200-CX). Для этого приготовлены поперечные срезы, проходящие через диагонали отпечатков (рис. $1, b)$. Образцы были вырезаны и утонены непосредственно в двухлучевом электронно-ионном микроскопе ZEISS CrossBeam AURIGA с использованием сфокуси- рованного ионного пучка (ионы $\mathrm{Ga})$. Утоненные образцы размером $5 \times 12 \mu \mathrm{m}$ приваривались к электронномикроскопической медной сеточке.

\section{3. Результаты и обсуждение}

3.1. ТЕМ-исследование квазикристаллического сплава $i-\mathrm{Al}_{62.4} \mathrm{Cu}_{25.3} \mathrm{Fe}_{12.3}$ в окрестности отпечатка индентора. ТЕМ-исследование поперечного среза в окрестности отпечатков индентора обнаруживает область напряженно-деформированного состояния квазикристаллического сплава. При пиковых нагрузках 50 и $75 \mathrm{mN}$ радиус этой области под отпечатком индентора составляет около 1.5 размера отпечатка $(\sim 3-4 \mu \mathrm{m})$. Согласно модели Джанокопулоса и Суреша для отпечатка с острым индентором [14,23], указанная область включает зону гидростатического давления около нескольких десятых размера отпечатка, то есть непосредственно под отпечатком, и располагающуюся ниже упругопластическую зону. Рассмотрим сначала результаты ТЕМ-исследований для пластической зоны. Именно в пластической зоне структурное состояние может определяться деформационным поведением, связанным с собственными механическими свойствами, а не с возможными фазовыми превращениями, индуцированными высоким давлением. В этом случае фазовые превращения происходят только в гидростатической зоне и вблизи нее [13].

На светлопольных и темнопольных изображениях в области упругопластической деформации индентированного квазикристаллического сплава наблюдается ряд систем параллельных линий - границ. Анализ показывает, что эти границы всегда параллельны следам наиболее плотноупакованных плоскостей с осями симметрии пятого $(A 5)$ и второго (A2) порядка. На рис. 2 представлены темнопольные и светлопольное изображения структуры квазикристаллического сплава в окрестности отпечатка в пластической зоне $\left(P_{\max }=75 \mathrm{mN}\right.$, индентор Берковича). Можно выделить две системы границ, каждая из которых образует почти параллельные блоки (рис. 2, $a, b)$. Стереографический анализ показал, что эти границы параллельны следам наиболее плотноупакованных плоскостей квазикристаллической структуры с осями симметрии пятого порядка $A 5$. В окрестности границ наблюдаются сильные экстинкционные контуры (рис. 2,a), что указывает на высокие упругие напряжения. На отдельных участках границ с осями $A 5_{1}$ наблюдается контраст, отвечающий дислокациям (рис. $2, b$ ).

Микродифракционные картины (рис. 3, $a$ ), полученные с областей, насыщенных этими границами, не выявляют никаких дифракционных эффектов, связанных с образованием в квазикристаллической фазе возможных деформационных двойников [24]. Не наблюдаются и дифракционные рефлексы от прослоек пентагональных и аппроксимантных фаз $[25,26]$, что подтверждает отсутствие в этой области фазовых превращений квазикристалл $\rightarrow$ аппроксимант, индуцированных высоким 
давлением. На дифракционных картинах присутствуют лишь рефлексы от поверхностных слоев $\beta$-фазы, образующейся при ионном утонении образцов, и соответствующие им рефлексы двойной дифракции. Все эти
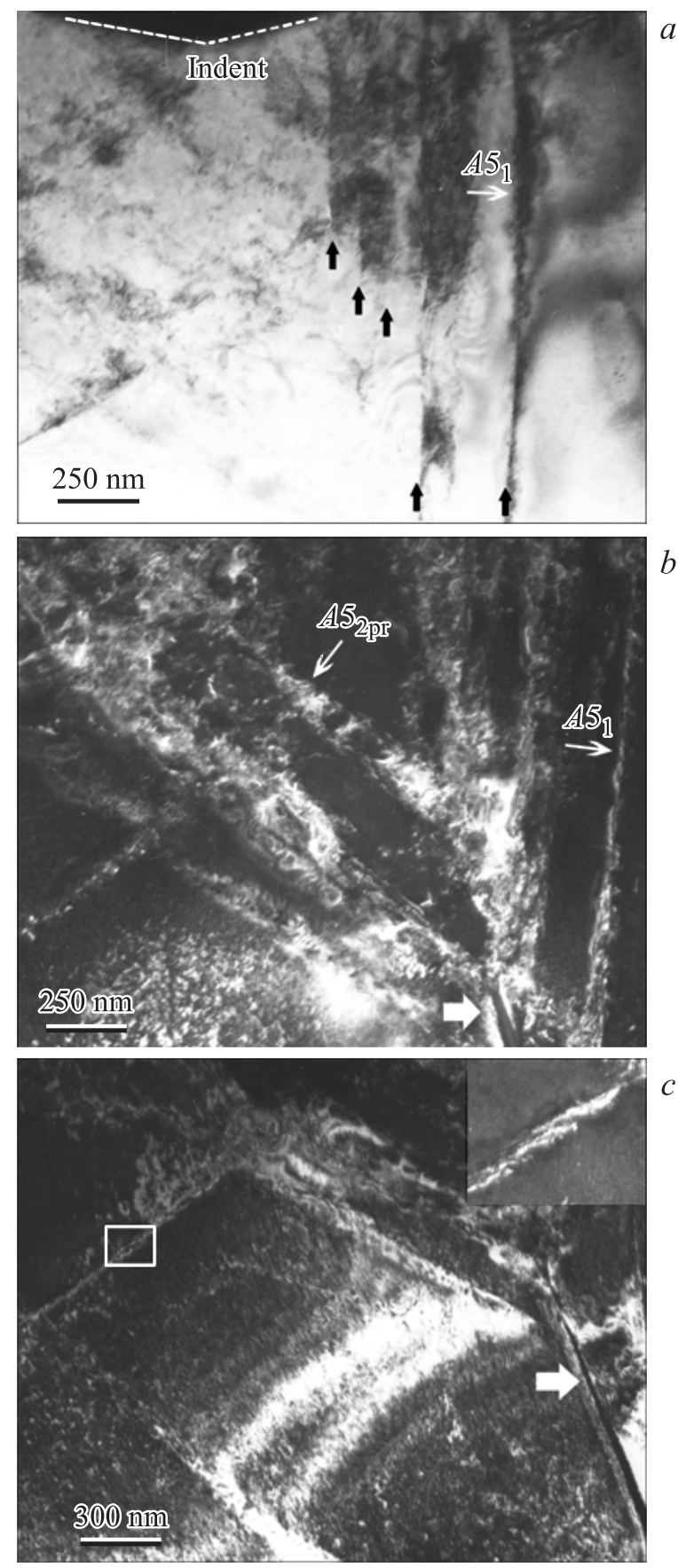

Рис. 2. Электронно-микроскопические изображения поперечного среза образца $i-\mathrm{Al}_{62.4} \mathrm{Cu}_{25.3} \mathrm{Fe}_{12.3}$ в окрестности отпечатка индентора, $P_{\max }=75 \mathrm{mN}$. Ориентация фольги вблизи оси $A 2$. Видны две системы границ, параллельные следам плоскостей с осями симметрии $A 5_{1}$ и $A 5_{2}$. $(a)-$ светлопольное и $(b, c)$ темнопольные изображения. Из границы зерна с равновесной дислокационной структурой (на вставке) распространяется трещина (белая стрелка). Край отпечатка указан штриховой линией $(a)$.

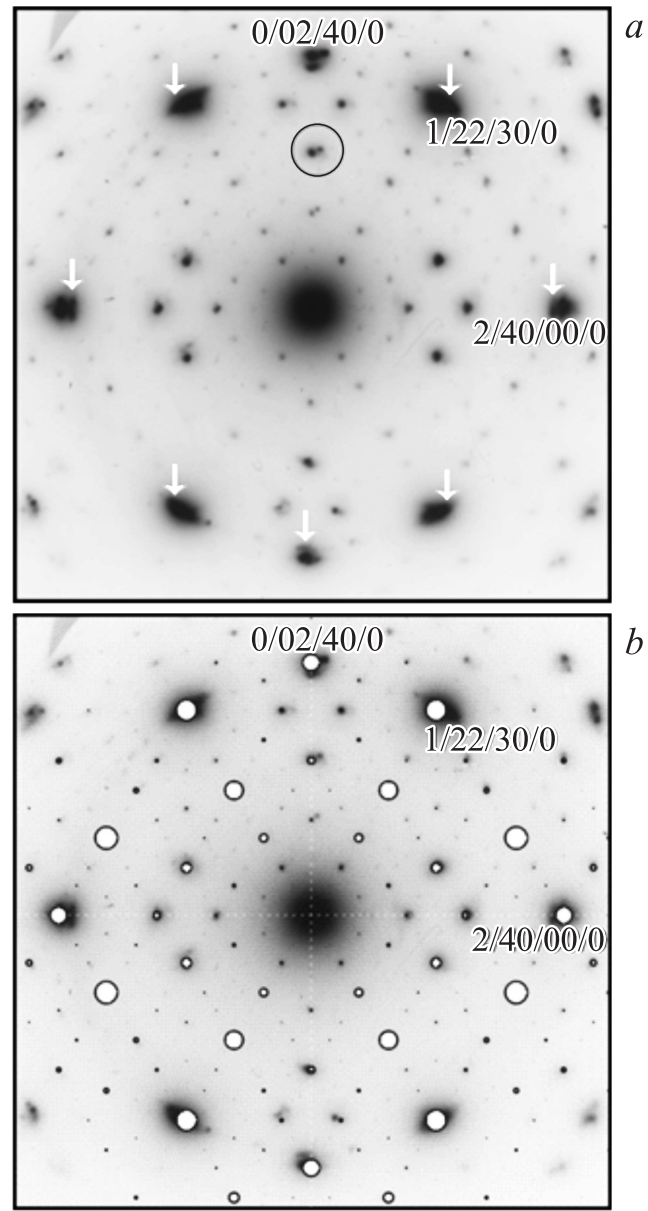

Рис. 3. Дифракционная картина сплава $i-\mathrm{Al}_{62.4} \mathrm{Cu}_{25.3} \mathrm{Fe}_{12.3}$ в пластической зоне в окрестности отпечатка; ориентация фольги в направлении $[0 / 0$ 0/0 0/2], ось $A 2(a)$. Эффект малоугловой разориентации квазикристаллической решетки отмечен кружком, стрелками указаны рефлексы от поверхностного $\beta$-слоя. (b) - расчетное сечение обратной решетки $i$-фазы в направлении $[0 / 00 / 00 / 2]$, интенсивность рефлексов пропорциональна размеру пятна.

дифракционные эффекты полностью идентичны рефлексам от неиндентированных участков (рис. 4, вставки). Сопоставление с расчетной дифракционной картиной не выявляет смещения рефлексов из позиций, характерных для квазипериодического порядка (рис $3, b$ ), но отмечается ослабление или исчезновение малоинтенсивных рефлексов. Азимутальные размытия и разориентации дифракционных рефлексов квазикристаллической фазы в пластической зоне составляют несколько градусов; размытия отсутствуют на дифракционных картинах, полученных от зерен вдали от отпечатка индентора. Все это позволяет рассматривать образующуюся в упругопластической зоне структуру как результат формирования деформационных полос дислокационного типа по наиболее плотноупакованным плоскостям квазикристаллической структуры. Широкие полосы интенсивного сложного контраста с признаками дислокаций становят- 


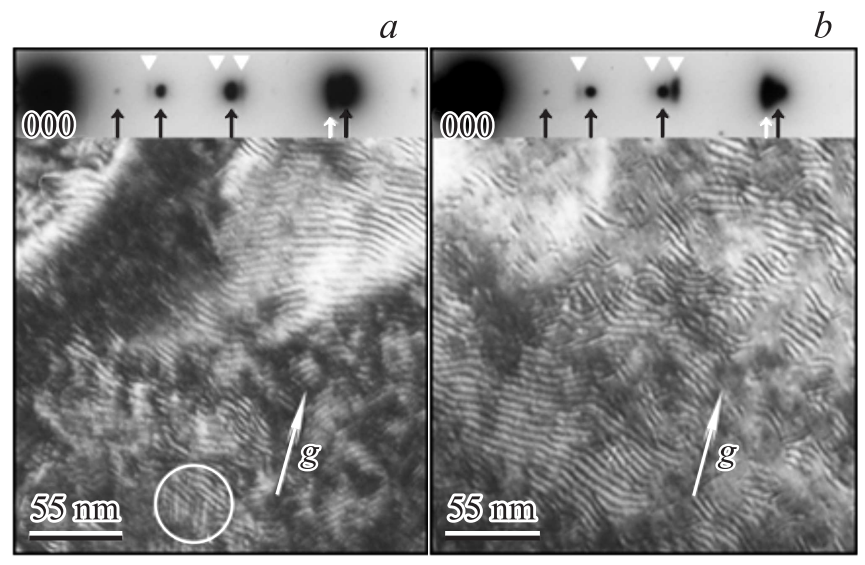

Рис. 4. Темнопольные изображения сплава $i-\mathrm{Al}_{62.4} \mathrm{Cu}_{25.3} \mathrm{Fe}_{12.3}$ в рефлексах $(2 / 40 / 0$ 0/0)і и (110) $\beta$ вблизи зоны гидростатического давления под отпечатком $(a)$ и вдали от отпечатка индентора $(b)$. Наноразмерная область (отмечена кружком) наложения одномерного муарового контраста от $\beta$-частицы в квазикристаллической матрице и от поверхностного $\beta$-слоя. На вставках рефлексы $i$-фазы вдоль оси $A 2$ (черные стрелки), рефлекс типа (110) $\beta$ (белая стрелка) и эффекты двойной дифракции (треугольники).

ся видны при отклонении деформационных полос от нормали к фольге; пример - полосы, перпендикулярные проекции оси $A 5_{2}$, (рис. 2, $b$ ).

Формирование деформационных полос, таким образом, характеризует собственное пластическое поведение хрупкой полизеренной квазикристаллической фазы $\mathrm{Al}-\mathrm{Cu}-\mathrm{Fe}$ при наноиндентировании, в условиях высоких давлений и одноосной нагрузки. В зоне деформации для обеих пиковых нагрузок выявляются подповерхностные трещины, которые распространяются, как правило, от дислокационных границ исходной зеренной структуры (рис. 2, $b, c$ ). Существенным является то, что ряд деформационных полос, как можно видеть, берет начало от вершины широкой части трещины. Есть полосы, которые распространяются от трещин с шириной раскрытия не более 3-4 nm. Следовательно, образование деформационных полос не только самостоятельный процесс пластической деформации, но и сопровождает остановку хрупкого раскрытия подповерхностных микро- или нанотрещин. Ранее значительно более высокую концентрацию границ и микротрещин обнаружили при исследовании поперечных сечений квазикристаллического монозеренного сплава $\mathrm{Al}-\mathrm{Pd}-\mathrm{Mn}$, продеформированного индентором при больших пиковых нагрузках $\left(P_{\max }=100\right.$, $500 \mathrm{mN}$ ) [15]. Однако кристаллография границ не была выявлена, не предполагалась и дислокационная структура границ. Сделанный нами вывод о залечивании трещин не противоречит результатам исследований полизеренного квазикристаллического сплава $\mathrm{Al}-\mathrm{Cu}-\mathrm{Fe}$, деформированного скретч-тестом [17], где испускание ряда дислокаций было обнаружено при раскрытии трещины от границы зерна. Кроме того, в полизеренном квазикри- сталлическом массивном сплаве $\mathrm{Al}-\mathrm{Pd}-\mathrm{Mn}$, деформированном в условиях высокого гидростатического давления в сочетании с одноосной нагрузкой [6], установлено образование деформационных полос дислокационного типа в плоскостях с осью симметрии $A 5$, что рассматривалось авторами как результат залечивания трещин.

Как отмечалось выше, при наноиндентировании деформационное поведение, связанное с фазовыми превращениями, индуцированными высокими давлениями, следует ожидать в области гидростатического давления и вблизи нее [13]. Для квазикристаллической фазы $\mathrm{Al}-\mathrm{Cu}-\mathrm{Fe}$, эти превращения не только в аппроксимантные или модулированные фазы $[25,26]$, которые не обнаружены в наших экспериментах, но и в кристаллическую $\beta$-фазу с образованием наноразмерных частиц, как установлено при скретч-тесте квазикристаллической фазы $\mathrm{Al}-\mathrm{Cu}-\mathrm{Fe}$ [17]. На темнопольных или светлопольных электронно-микроскопических изображениях образование частиц $\beta$-фазы в квазикристаллической матрице $\mathrm{Al}-\mathrm{Cu}-\mathrm{Fe}$ обычно обнаруживается по эффектам муарового контраста благодаря ориентационным соотношениям $\beta$ - и $i$-фаз [17], а также близости модулей совпадающих векторов обратной решетки $\left(\left|\mathbf{g}_{\overline{1} 10 \beta}\right|=1 / 2.075 \AA,\left|\mathbf{g}_{\|}(2 / 40 / 00 / 0)_{i}\right|=1 / 2.01 \AA^{-1}\right.$, $\left.\mathbf{g}_{\|}(1 / 22 / 30 / 0)_{i} \mid=1 / 2.11 \AA^{-1}\right)$. В данной работе анализ признаков образования $\beta$-частиц в квазикристаллической матрице, индуцированного индентированием, проводится в присутствии превращения, связанного с формированием на поверхности квазикристаллической фазы тонких участков $\beta$-фазы под воздействием ионного утоняющего пучка. Обнаружено, что характеристики одномерного муарового контраста (периоды и углы разворота полос к вектору действующего отражения) от поверхностных слоев $\beta$-фазы на участках вдали от отпечатка и в основной части пластической зоны не имеют заметных отличий (рис. 4). С приближением к зоне гидростатического давления (несколько десятых долей от размера отпечатка) муаровый контраст усложняется; появляются множественные эффекты наложения картин одномерного муара в наноразмерных областях (отмечено на рис. $4, b$ ), что мы связываем с наложением эффектов контраста от $\beta$-частиц в квазикристаллической матрице и от поверхностных $\beta$-слоев.

Таким образом, ТЕМ-исследование поперечного среза квазикристаллического сплава $i$ - $\mathrm{Al}_{62.4} \mathrm{Cu}_{25.3} \mathrm{Fe}_{12.3}$ в окрестности отпечатка индентора $\left(P_{\max }=75,50 \mathrm{mN}\right)$ установило зону пластической деформации радиусом до 1.5 размеров отпечатка индентора, микроструктура которой определяется собственным деформационным поведением квазикристаллической фазы, не связанным с фазовыми превращениями квазикристалл-аппроксимант. Пластическая зона содержит несколько систем деформационных полос, залегающих по наиболее плотноупакованным плоскостям с осями симметрии пятого и второго порядка. Они формируют блочную структуру с разориентацией решетки до нескольких градусов и начинаются нередко от микро- и наноразмерных под- 
поверхностных трещин. Формирование деформационных полос дислокационного типа рассматривается и как самостоятельный процесс пластической деформации и как результат остановки хрупкого раскрытия подповерхностных трещин в квазикристаллическом сплаве при индентировании. Обнаружены признаки индуцированного высоким давлением образования наноразмерных частиц $\beta$-фазы в области гидростатического давления (около нескольких десятых размера отпечатка индентора).

В следующем разделе представим характеристики кривых нагрузка $(P)$-смещение $(h)$ полизеренного квазикристаллического сплава $i-\mathrm{Al}_{62.4} \mathrm{Cu}_{25.3} \mathrm{Fe}_{12.3}$, полученных при формировании исследованных выше отпечатков наноиндентора. Оценим соотношение вкладов (прерывистой и монотонной) пластической деформации, рассмотрим возможные механизмы этих вкладов, используя результаты структурного ТЕМ-исследования окрестности отпечатков индентора.

3.2. Диаграммы индентирования $P-h$ и деформационное поведение полизеренного квазикристаллического $\quad$ сплава $i-\mathrm{Al}_{62.4} \mathrm{Cu}_{25.3} \mathrm{Fe}_{12.3}$. На рис. 5, $a$ представлена типичная кривая нагрузка $(P)$-смещение $(h)$, характеризующая деформационное поведение полизеренного квазикристаллического сплава $i$ - $\mathrm{Al}_{62.4} \mathrm{Cu}_{25.3} \mathrm{Fe}_{12.3}$ при наноиндентировании с пиковой нагрузкой $P_{\max }=50 \mathrm{mN}$ и скоростью нагружения $2 \mathrm{mN} \cdot \mathrm{s}^{-1}$. В рамках подхода Оливера-Фарра [22], оценки твердости и модуля упругости, рассчитанные из кривых для нагрузок $P_{\max }=50$ и $P_{\max }=75 \mathrm{mN}$, состав-

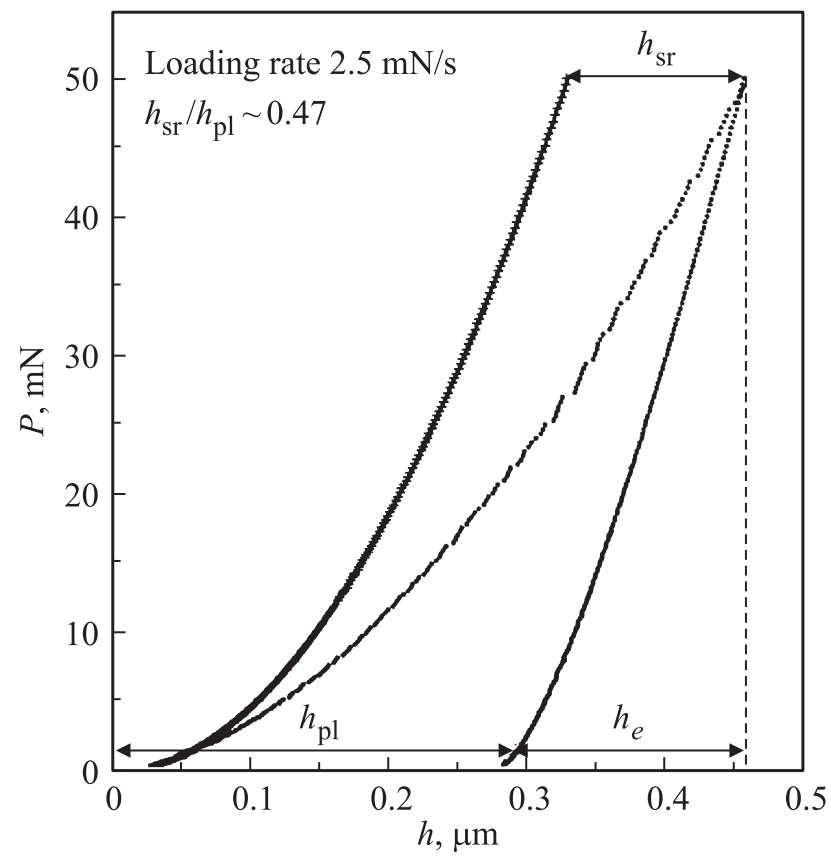

Pис. 5. Диаграмма $P-h$ квазикристаллического сплава $i$ - $\mathrm{Al}_{62.4} \mathrm{Cu}_{25.3} \mathrm{Fe}_{12.3}$ с множественными эффектами прерывистой деформации (ступени) на участке нагрузки и „консолидированная““ кривая нагрузки, исключающая эти эффекты. $h_{\mathrm{pl}}, h_{e}, h_{\mathrm{sr}}-$ смещения индентора, соответствующие вкладам пластической, упругой и прерывистой пластической деформации.

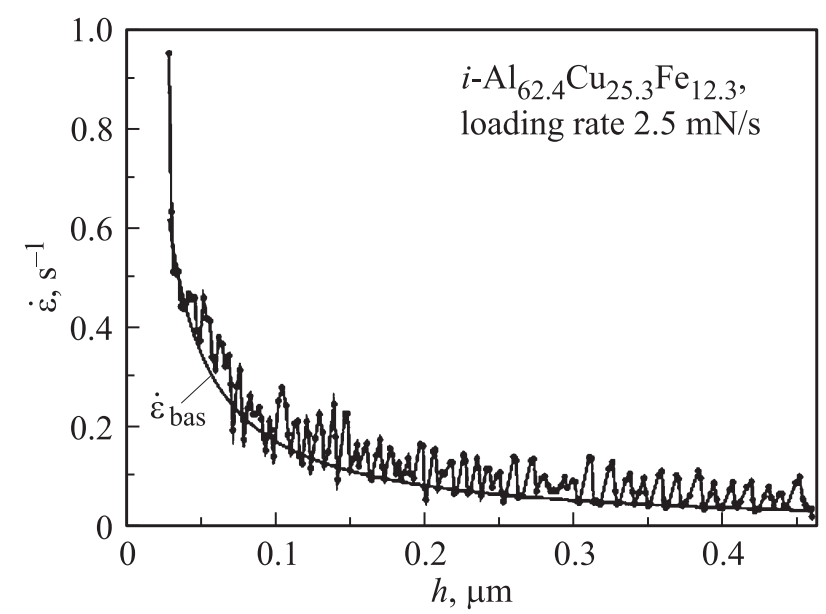

Рис. 6. Зависимость скорости относительной деформации от смещения индентора для полизеренного квазикристаллического сплава $i-\mathrm{Al}_{62.4} \mathrm{Cu}_{25.3} \mathrm{Fe}_{12.3}$. Построена базовая составляющая скорости деформации $\dot{\varepsilon}_{\text {bas }}$.

ляют $H=11.2 \pm 0.4 \mathrm{GPa}, E=197 \pm 5 \mathrm{GPa}$. Полученные оценки находятся в диапазоне значений, характерных для квазикристаллического сплава $i-\mathrm{Al}-\mathrm{Cu}-\mathrm{Fe}$ при указанных нагрузках $[11,18]$. На кривой наблюдаются множественные ступени, признаки нестабильной (или прерывистой) пластической деформации, характерные для полизеренных $[9,10,12,16]$ и для монозеренных [8] квазикристаллов. Ступени появляются при нагрузках несколько $\mathrm{mN}$, что согласуется с результатами, полученными для совершенных монозеренных квазикристаллов при использовании острого индентора [8]. На кривых $P-h$ сплава $\beta-\mathrm{Al}_{50} \mathrm{Cu}_{33} \mathrm{Fe}_{17}$, выбранного для сравнения, множественные ступени не выявляются.

Оценка вклада прерывистой деформации в общую деформацию для сплава $i-\mathrm{Al}_{62.4} \mathrm{Cu}_{25.3} \mathrm{Fe}_{12.3}$ сделана из зависимости скорости относительной деформации $(\dot{\varepsilon})\left(\frac{d h}{h d t}\right)$ от смещения индентора $h$. Кривая $\dot{\varepsilon}-h$ демонстрирует последовательность пиков, соответствующих резкому повышению $(\dot{\varepsilon})$ на ступени, и базовый вклад $\dot{\varepsilon}_{\text {bas }}$, соответствующий составляющим монотонной пластической и упругой деформации (рис. 6). Амплитуда пиков имеет тенденцию постепенно снижаться, как и вклад базовой скорости деформации $\dot{\varepsilon}_{\text {bas }}$, соответственно множителю $\left(\frac{1}{h}\right)$. При этом суммарный вклад прерывистой пластической деформации в общую деформацию полизеренного квазикристаллического сплава оказывается значительным. Отношение суммарных мощностей прерывистой и общей деформации, рассчитанное как отношение величин

$$
\sum\left[\dot{\varepsilon}\left(h_{i}\right)-\dot{\varepsilon}_{\text {bas }}\left(h_{i}\right)\right] P\left(h_{i}\right) h_{i}
$$

$$
\sum\left[\dot{\varepsilon}\left(h_{i}\right)\right] P\left(h_{i}\right) h_{i},
$$

составляет порядка 0.3. Введение поправок на вклад от упругого прогиба поверхности дает значение около 0.38 . Эти результаты согласуются и с оценкой, сделанной методом Голдстоуна по „консолидированным кривым“ [27]. 
„Консолидированные кривые“ строятся исключением из нагрузочной ветви диаграммы эффектов прерывистой деформации и используются для оценки соотношений прерывистой и монотонной пластической деформации [28]. „Консолидированная кривая“, построенная интегрированием функции базовой скорости деформации $\dot{\varepsilon}_{b a s}$ и восстановлением функции $h(t)$, представлена на рис. $5, a$. Полученное отношение смещений индентора, соответствующих прерывистой и монотонной компоненте пластической деформации, составляет $\sim 0.9$.

Таким образом, для полизеренных однофазных сплавов $i$-AlCuFe в условиях развитых эффектов прерывистой деформации на кривых $P$ (нагрузка) $-h$ (смещение), когда ступени начинают появляться уже при нескольких $\mathrm{mN}$, неупругая деформация при наноиндентировании имеет существенный вклад прерывистой деформации (по оценкам суммарного смещения индентора и суммарной мощности). Согласно предположениям большинства исследований [8-10], прерывистая деформация связана с фазовым превращением, индуцированным высоким давлением, в частности, в $\beta$-фазу. Однако, по данным ТЕМ-исследования, проведенного в нашей работе, это фазовое превращение имеет место только в узкой зоне гидростатического давления, непосредственно под отпечатком индентора.

Следуя модели о влиянии фазового превращения на эффекты изменения давления под индентором [13], мы полагаем, что превращение с образованием $\beta$-фазы, протекающее в узкой зоне под индентором, не дает существенного вклада в наблюдаемые на зависимости $P-h$ ступени и скачки. Прерывистый вклад пластической деформации, по нашему мнению, следует в основном связать с собственным деформационным поведением квазикристаллической фазы, то есть с образованием множества деформационных полос дислокационного типа, наблюдаемых во всей упругопластической зоне, в том числе и в головной части подповерхностных трещин. Дискретный акт пластической деформации, связанный с активацией и прохождением отдельной полосы деформации, будет сопровождаться появлением ступени (эффекта нестабильности), как и в случае фазового превращения, на диаграмме $P-h$. При этом, отдельные ступени и скачки на кривых могут включать некоторый вклад, соответствующий стадиям образования подповерхностных трещин, как и в случае хрупких материалов [29], подобных квазикристаллам. Монотонная деформация предположительно осуществляется движением вторичных деформационных полос, для которых может быть заметно снижен активационный порог, и индивидуальных дислокаций переползания, механизм активации которых под наноиндентором был предложен в работе [16].

\section{4. Заключение}

Выполнено электронно-микроскопическое и электронно-дифракционное исследование поперечных сре- зов квазикристаллического сплава $i$ - $\mathrm{Al}_{62.4} \mathrm{Cu}_{25.3} \mathrm{Fe}_{12.3}$ в окрестности отпечатков индентора $\left(P_{\max }=75,50 \mathrm{mN}\right)$, характеризующихся эффектами прерывистой деформации на диаграммах нагружения $P-h$.

Установлена зона упруго-пластической деформации радиусом до 1.5 размеров отпечатка индентора, микроструктура которой определяется собственным деформационным поведением квазикристаллической $i$-фазы. В пластической зоне наблюдается несколько систем деформационных полос, залегающих по плотноупакованным плоскостям с осями симметрии пятого и второго порядка. Они формируют блочную структуру с разориентацией решетки до нескольких градусов и начинаются часто от микро- и наноразмерных подповерхностных трещин. Признаки образования наноразмерных частиц $\beta$-фазы обнаружены в узкой области гидростатического давления непосредственно под отпечатком (несколько десятых долей размера отпечатка).

Формирование деформационных полос дислокационного типа рассматривается и как самостоятельный процесс пластической деформации и как результат остановки хрупкого раскрытия подповерхностных трещин в квазикристаллическом сплаве при наноиндентировании.

Эффекты прерывистой деформации на диаграммах $P-h$ сплава $i-\mathrm{Al}_{62.4} \mathrm{Cu}_{25.3} \mathrm{Fe}_{12.3}$, которые составляют существенный вклад в общую пластическую деформацию (по оценкам до 50\%), связываются в основном с активацией и прохождением деформационных полос, а также с начальными стадиями образования подповерхностных трещин. Предполагается, что фазовое превращение с образованием частиц $\beta$-фазы в тонком слое под индентором вносит малый вклад в эффекты прерывистой деформации.

Электронно-микроскопические исследования проведены в ЦКП УрО РАН „Электронная микроскопия“. Авторы выражают благодарность А.Н. Уксусникову за техническую помощь в приготовлении электролитически полированных образцов, а также ЦКП уникального оборудования УрФУ им. Б.Н. Ельцина и М.С. Карабаналову за подготовку образцов методом сфокусированного ионного пучка.

\section{Список литературы}

[1] S. Pedrazzini, M. Galano, F. Audebert, D.M. Collins, F. Hofmann, B. Abbey, A.M. Korsunsky, M. Lieblich, A. Garcia Escorial, G.D.W. Smith. Mater. Sci. Eng. A 375-377, 175 (2016).

[2] B. Markoli, T. Boncina, F. Zupanic. Mat.-wiss. U Werkstofftech. 43, 340 (2012).

[3] S. Olsson, E. Broitman, M. Garbrecht. J. Mater. Res. 31, 232 (2016).

[4] M. Feuerbacher, K. Urban. Plastic behaviour of quasicrystalline materials, in Quasicrystals, Structure and Physical Properties / Ed. H.R. Trebin. Wiley-VCH, Weinheim (2003). P. 432.

[5] F. Mompiou, D. Caillard. Comp. Rendus Phys. 15, 82 (2014). 
[6] M. Texier, A. Proult, J. Bonnevielle, J. Rabier, N. Baluc, P. Cordier. Scripta Mater. 49, 47 (2003).

[7] J. Fikar, J. Bonneville, J. Rabier, N. Baluc, A. Proult, P. Cordier, I. Stretton. Mater. Res. Soc. Symp. Proc. 643, K7.4.1-K7.4.6. (2001).

[8] P. Paufler, B. Wolf. Deformation of quasicrystals by indentation, in Quasicrystals, Structure and Physical Properties / Ed. H.R. Trebin. Wiley-VCH, Weinheim (2003). P. 501.

[9] J. Von Steubut, C. Strobel, J.M. Dubois. In: Proceedings 5th Int. Conference on Quasicrystals, Avignon, 1995 / Eds C. Jano, R. Mosseri. World Scientific, Singapore (1995). P. 704.

[10] S.N. Dub, Yu.V. Milman, D.V. Lotsko, A.N. Belous. J. Mater Sci. Lett. 20, 1043 (2001)

[11] J.M. Dubois. Useful quasicrystals. World Scientific Publishing, Singapore (2005). P. 462.

[12] Ю.Н. Головин, С.Н. Дуб, В.И. Иволгин, В.В. Коренков, А.И. Тюрин. Изв. РАН, Сер. физ. 68, 1428 (2004).

[13] V. Domnich, Y. Gogotsi. Rev. Adv. Mater. Sci. 3, 1 (2002).

[14] Ю.Н. Головин. Наноиндентирование и его возможности, Машиностроение, М. (2009). С. 312.

[15] M. Wollgarten, H. Saka. Phil. Mag. A. 79, 2195 (1999).

[16] В.М. Ажажа, С.С. Борисов, С.Н. Дуб, С.В. Малыхин, А.Т. Пугачев, Б.А. Мерисов, Г.Я. Хаджай. ФТТ 47, 2170 (2005).

[17] J.S. Wu, V. Brien, P. Brunet, C. Dong, J.M. Dubois. Phil. Mag. A 80, 1645 (2000).

[18] Е.В. Шалаева, Ю.В. Чернышев, Е.О. Смирнова, С.В. Смирнов. ФТТ 55, 2095 (2013).

[19] J.W. Cahn, D. Shechtman, D. Gratias. J. Mater. Res. 1 (1986) 13-26.

[20] C. Jano. Quasicrystals. Clarendon Press, Oxford (1994). P. 423.

[21] J.D. Rzepski, A. Quivy, Y. Calvayrac, M.C. Quiquandon, D. Gratias. Phil. Mag. B 60, 855 (1989).

[22] W.C. Oliver, G.M. Pharr. J. Mater. Res. 7, 1564 (1992).

[23] A.E. Giannakopoulos, S. Suresh. Scripta Mater. 40, 1191 (1999).

[24] J.E. Shield. Phil. Mag. Lett. 69, 115 (1994).

[25] N. Menguy, M. Auder, P. Guyot, M. Vacher. Phil. Mag. B 68, 595 (1993).

[26] M. Quiquandon, A. Quivy, J. Devaud, F. Faudot, S. Lefebvre, M. Bessiere, Y. Calvayrac. J. Phys.: Condens. Matter 8, 2487 (1996).

[27] A. Gouldstone, H.J. Kon, K.Y. Zeng, A.E. Giannakopoulos, S. Suresh. Acta Mater. 48, 2277 (2000).

[28] C.A. Schuh, T.G. Nieh. Acta Mater. 51, 87 (2003).

[29] D.J. Oliver, S. Ruffell, J.E. Bradly, J.S. Williams, M.V. Swain, P. Munroe, P.J. Simpson. Phys. Rev. B 80, 115210 (2009). 